\title{
PURWARUPA PENGIRIMAN INFORMASI KETINGGIAN AIR SUNGAI MELALUI SHORT MESSAGE SERVICE(SMS) BERBASIS ARDUINO UNO
}

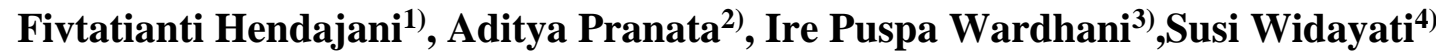

\author{
${ }^{1,2}$ Sistem Komputer,Sekolah Tinggi Manajemen Informatika dan Komputer STI\&K, Jalan BRI Radio Dalam \\ No 17, Jakarta Selatan \\ email:fivtatiantihendajani@gmail.com, \\ email:aditya.pranata48@gmail.com \\ ${ }^{3}$ Teknologi Informasi, Sekolah Tinggi Manajemen Informatika dan Komputer STI\&K. Jalan BRI Radio \\ Dalam No17, Jakarta Selatan \\ email: irepuspa@gmail.com \\ ${ }^{4}$ Sistem Informasi, Sekolah Tinggi Manajemen Informatika dan Komputer STI\&K. Jalan BRI Radio Dalam \\ No17, Jakarta Selatan \\ email:widayatisusi@gmail.com
}

\begin{abstract}
The development of life and technology at this time is felt to be faster and demands changes in various sectors. Rapid technological advances allow for various businesses to provide convenience and comfort for humans. One of them is through the development of a river water level detection system design. Checking the river water level is usually carried out by monitoring officers. This can be dangerous for officers because the arrival of water is unpredictable. Then the information will be forwarded to the monitoring post and then if needed, residents will ask for news on river water levels by telephone. Information can be felt too late if what happened was a flood of shipments. Residents did not have time to be able to save their lives and property. The river water level information delivery system using Short Massege Service (SMS) can be the solution. Detecting river water levels using a water level which is then processed using Arduino will produce a siren sound and turn on an indicator that indicates the water exceeds the predetermined limit, this can cause flooding. The system will send a short message to authorized residents in the Watershed (DAS) so that they can convey this information to residents immediately. The result of the research is a prototype that has been through trials and the results are in accordance with the research objectives, namely water level information can be sent immediately.
\end{abstract}

Keywords: Information, water level, flood, Arduino Uno, SMS

\begin{abstract}
Abstrak
Perkembangan kehidupan dan teknologi pada saat ini dirasakan semakin cepat dan menuntut adanya perubahan di berbagai sektor. Kemajuan teknologi yang sangat pesat memungkinkan adanya berbagai usaha memberikan kemudahan dan kenyamanan bagi manusia. Salah satunya adalah melalui pengembangan perancangan sistem pendeteksi ketinggian air sungai. Pengecekan ketinggian air sungai biasanya dilakukan oleh petugas pemantauan. Hal ini dapat membahayakan petugas dikarenakan datangnya air tidak dapat diprediksi. Lalu informasi tersebut akan diteruskan ke pos pemantauan dan kemudian jika diperlukan warga akan menanyakan berita ketinggian air sungai melalui telepon. Informasi bisa dirasakan terlambat jika yang terjadi merupakan banjir kiriman. Warga tidak sempat untuk dapat menyelamatkan nyawa dan harta bendanya. Sistem penyampaian informasi ketinggian air sungai menggunakan Short Massege Service (SMS) dapat menjadi solusinya. Pendeteksi
\end{abstract}


ketinggian air sungai menggunakan water level yang kemudian diolah menggunakan Arduino akan menghasilkan bunyi sirene dan menyalakan indikator yang menandakan air melampaui batas yang telah ditetapkan, Hal ini dapat menyebabkan terjadinya banjir. Sistem akan mengirimkan pesan singkat kepada warga yang berwenang yang berada di Daerah Aliran Sungai (DAS) agar dapat menyampaikan informasi tersebut ke warga dengan segera. Hasil penelitian berupa purwarupa yang telah melalui ujicoba dan didapat hasilnya sesuai dengan tujuan penelitian yaitu informasi ketinggian air dapat segera dikirimkan .

Kata kunci : Informasi, ketinggian air, banjir, Arduino Uno, SMS

\section{PENDAHULUAN}

Bencana alam merupakan salah satu bencana alam yang timbul akibat tindakan manusia yang berbuat ceroboh dan merusak. Bencana alam apapun itu pasti akan menimbulkan kerugian, baik itu material maupun psikologis. Bencana alam menyebabkan banyak orang kehilangan tempat tinggal, sumber mata pencaharian, anggota keluarga, bencana alam juga dapat menimbulkan trauma bagi korbankorbannya. Karena itu, bancana alam apapun harus dikurangai dampaknya agar demi tercapainya hidup yang aman dan tenteram. Salah satu jenis bencana alam itu adalah banjir.

Banjir yang timbul di Jakarta biasanya terjadi akibat meluapnya sungai Ciliwung karena debit air yang sangat deras mengalir dari dataran yang lebih tinggi seperti dari kota Bogor dan sekitanya dan banjir ini sering di sebut dengan banjir kiriman, Akibat membuang sampah sembarangan ke sungai juga menjadi salah satu penyebabnya karna dapat menghambat aliran air. Ketika air sungai tidak dapat lagi meneruskan atau mengalirkan air tersebut, air akan meluap kedaratan. Banjir biasanya terjadi ketika hujan turun deras secara terus menerus. Banjir tidak hanya merusak barang berharga serta lingkungan, membahayakan hidup manusia dan binatang, namun banjir juga mempunyai efek lain juga. Banyak warga yang kehilangan tempat tinggal,terputusnya akses jalan di daerah yang terkena banjir dan wabah penyakit. Banyak pelajar tidak bisa sekolah, karena sekolahnya terendam banjir. Untuk dapat mengetahui ketinggian air sungai, ada petugas yang siaga mengawasi ketinggian air sungai di tempat pengukuran ketinggian air sungai. Lalu informasi ketinggian air akan disampaikan ke petugas yang berwenang yang diharapkan dapat menyalurkan informasi di Daerah Aliran Sungai (DAS). Hal ini pun juga membahayakan petugas pemantau dalam melakukan tugasnya. Namun terkadang informasi ketinggian air sungai sulit didapatkan. Ada beberapa nomer telepon yang dapat dihubungi untuk mendapatkan informasi ketinggian air sungai namun dalam kondisi darurat sulit untuk terhubung.

Berdasarkan latar belakang diatas maka identifikasi masalah adalah bagaimana cara agar dapat mendeteksi ketinggian air tanpa membahayakan petugas pantau. Informasi ketinggian air juga dapat diteruskan ke pihak yang berwenang sepanjang DAS. Maka akan dibuat purwarupa penyampaian informasi ketinggian air sungai. Purwarupa menggunakan Water Level untuk dapat mendeteksi ketinggian air yang akan diproses oleh Arduino Uno lalu menyampaikan pesan singkat melalui modul SIM800L kebeberapa pos pemantauan yang berada sepang DAS

Tujuan pembuatan purwarupa adalah penyampaian informasi ketinggian air dapat dilakukan lebih cepat tanpa membahayakan petugas pantau. Informasi ketinggian air dapat dilakukan agar masyarakat yang berada DAS dapat 
bersiap siap menyelamatkan diri, harta benda dan dokummen yang berharga. Harapannya purwarupa dapat dikembangkan menjadi sistem sesungguhnya yang dapat diterapkan pada pos pantau ketinggian air yang dapat menyebabkan banjir kiriman.

Penelitian terdahulu yang terkait dengan ketinggian air dengan judul Sistem monitoring dan peringatan ketinggian air berbasis WEB dan SMS Gateway oleh Alfred Tenggono, Yovan Wijaya, Erick Kusuma. Dalam artikelnya dikatakan sistem pemantau ketinggian air dapat dilakukan dan ditampilkan secara online ini akan lebih mempermudah proses pemantauan ketinggian air dimana pun dan kapan pun diperlukan melalui halaman website namun tidak semua lokasi mendapatkan sinyal internet yang baik sehingga alternatifnya juga menggunakan SMS asal nomer telepon tujuan harus didaftarkan agar dapat dikirimkan informasi ketinggian air terbaru [1]. Penelitiaan yang menggunakan SMS dilakukan [2]. Kebutuhan informasi penting bagi siswa salah satunya adalah informasi yang berkaitan dengan penyelesaian pendidikan, perangkat yang dirancang dalam penelitian ini akan menjadi salah satu solusi untuk memudahkan siswa menerima informasi secara real-time.

Informasi adalah data yang telah diolah menjadi sebuah bentuk yang berarti bagi penerimanya dan bermanfaat bagi pengambilan keputusan saat ini atau mendatang [3]. Raymond Mc.leod menyatakan bahwa informasi adalah data yang telah diolah menjadi bentuk yang memiliki arti bagi si penerima dan bermanfaat bagi pengambilan keputusan saat ini atau mendatang [4].

Mikrokontroller adalah sebuah chip yang berfungsi sebagai pengontrol susunan rangkaian elektronik yang dapat menyimpan program didalamnya.
Mikrokontroller umumnya terdiri dari Central Processing Unit (CPU), memori, Input Output (I/O) dan unit pendukung lainya. Dengan kata lain, mikrokontroller adalah suatu alat elektronika digital yang mempunyai masukan dan keluaran serta kendali dengan program yang bisa ditulis dan dihapus secara khusus [5].

Arduino adalah kit elektronik atau papan pengendali rangkaian elektronik yang bersifat open-source, diturunkan dari Wiring platform yang dirancang untuk memudahkan penggunaan elektronik dalam berbagai bidang. Perangkat keras nya memiliki prosesor Atmel Automatic Voltage Regulator (AVR). Peranti ini dapat dimanfaatkan untuk mewujudkan rangkaian elektronik dari yang sederhana hingga yang kompleks. Pengendalian Light Emitting Diode (LED), mengontrol helikopter, penggerak servo hingga pengontrolan robot juga dapat di implementasikan dengan penambahan komponen tertentu sesuai apa yang ingin digunakan [6].

Arduino Uno adalah sebuah papan sirkuit berbasis mikrokontroller ATmega328. Integrated Circuit (IC) ini mempunyai 14 input/output digital (6 output untuk Pulse Width Modulation (PWM), 6 analog input, resonator kristal keramik $16 \mathrm{MHz}$, Koneksi Universal Serial Bus (USB), soket adaptor, pin header In Circuit Serial Programming (ICSP), dan tombol reset. Hal inilah yang dibutuhkan untuk mensupport mikrokontroller secara mudah terhubung dengan kabel power USB, kabel power supply adaptor AC ke DC dan baterai. Berikut bentuk dari papan Arduino Uno lebih jelasnya dapat dilihat pada gambar 1 . 


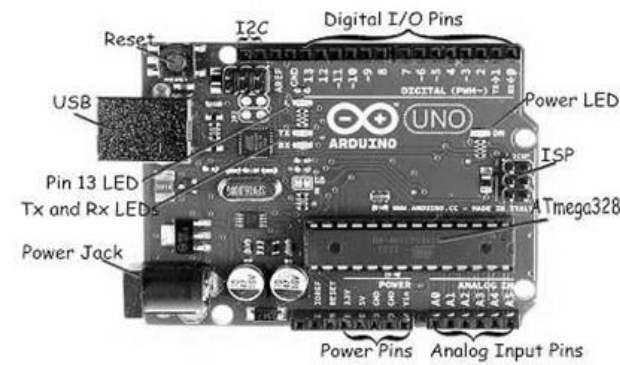

Gambar 1. Arduino Uno Atmega 328

Arduino Uno dilengkapi dengan static random-access memory (SRAM) berukuran $2 \mathrm{~KB}$ untuk memegang data flash memory berukuran $32 \mathrm{~KB}$, dan erasable progammable read-only memory (EEPROM). SRAM digunakan untuk menampung data atau hasil pemrosesan data selama Arduino menerima pasokan catu daya. Flash memory untuk menaruh program yang dibuat. EEPROM digunakan untuk menaruh program bawaan data Arduino Uno dan sebagian lagi dapat dimanfaatkan untuk menaruh data milik anda secara permanen.

Prosesor jenis juga digunakan untuk industry kreatif dalam otomatisasi pewarnaan mesin sablon yang dilakukan [7].

Sensor adalah sesuatu yang digunakan untuk mendeteksi adanya perubahan lingkungan fisik atau kimia. Variable keluaran dari sensor yang diubah menjadi besaran listrik disebut transduser [8].

Pada saat ini, sensor telah dibuat dengan ukuran sangat kecil dengan orde nanometer. Ukuran yang sangat kecil ini sangat memudahkan permakaian dan menghemat energi. Jenis sensor [9] adalah sensor proximity, sensor magnet atau disebut juga relai buluh. Sensor ultrasonik bekerja berdasarkan prinsip pantulan gelombang suara. Sensor tekanan memiliki transduser yang mengukur ketegangan kawat, dimana mengubah tegangan mekanis menjadi sinyal listrik. Sensor Kecepatan (RPM) . Proses penginderaan sensor kecepatan. Sensor Penyandi (Encoder) digunakan untuk mengubah gerakan linear atau putaran menjadi sinyal digital. Sensor suhu yang umum digunakan, resistance temperature detector (RTD), termistor dan IC sensor [10].

Saat ini, ketinggian air dapat diukur secara mudah dengan menggunakan alat modern seperti Water Level. Pengertian Water Level sendiri adalah seperangkat alat yang digunakan untuk mengukur ketinggian air di tempat yang berbeda agar mendapatkan data perbandingan. Water level yang paling sederhana adalah sepasang pipa yang saling terhubung di bagian bawah. Water level sederhana akan mengukur ketinggian air melalui tinggi air di kedua pipa apakah sama atau tidak. Hasil pengukuran dari water level lebih rendah dari menggunakan laser tetapi water level mempunyai akurasi yang tinggi dalam pengukuran jarak jauh. Untuk menghindari kesalahan pengukuran dalam penggunaan water level, suhu pada air haruslah sama [11].

Water level dapat juga digunakan untuk mengukur tekanan air dengan menggunakan prinsip tekanan Hidrostatik. Air dalam suatu wadah selalu mendapatkan tekanan dari atmosfir dan sebanding dengan level dari air sehingga bisa didapatkan besar tekanan air. Saat ini, sudah ada water level yang lebih modern dimana water level modern dapat mengukur ketinggian dan tekanan air secara bersamaan dengan sensor dan hasil pengukurannya dapat direkam kemudian disimpan dalam bentuk data. Alat tersebut disebut dengan Sensor Water Level [12]. Gambar 2 adalah Modem SIM800L.
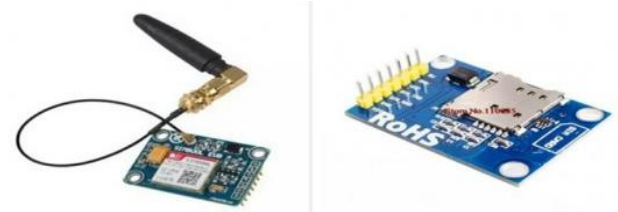

Gambar 2. Bentuk Fisik SIM800L

Modem GSM adalah sebuah perangkat elektronik yang berfungsi sebagai alat 
pengirim dan penerima pesan SMS. Sebuah modem GSM terdiri dari beberapa bagian, di antaranya adalah lampu indikator, terminal daya, terminal kabel ke komputer, antena dan untuk meletakkan kartu SIM [13].

Sistem pemantauan yang dilakukan dapat melalui media jarak jauh yaitu menggunakan GSM SIM800L V1 dengan memanfaatkan telepon seluler sebagai perantara komunikasi pada fitur pesan atau SMS telah dilakukan oleh [14] dan [15] dalam bidang yang berhubungan dengan kebakaran .

Flowchart menggambarkan urutan logika dari suatu prosedur pemecahan masalah, sehinggga flowchart merupakan langkah-langkah penyelesaian masalah yang dituliskan dalam simbol simbol tertentu [16].

\section{Bahasa Pemrograman Bahasa C}

Bahasa $\mathrm{C}$ adalah bahasa BCPL (Basic Combined Programming Language) yang dikembangkan oleh Martin Richard pada tahun 1967. Bahasa ini kemudian dikembangkan oleh Ken Thompson menjadi bahasa B pada tahun 1970. Perkembangan selanjutnya menjadi bahasa C oleh Dennis Riche sekitar tahun 1970 [17].

\section{METODE PENELITIAN}

Metode penelitian yang digunakan dalam penelitian ini adalah studi pustaka sumber-sumber kajian, penelitian terdahulu, landasan teori yang mendukung data informasi sebagai acuan dalam melakukan perencanaan dan perancangan sistem. Dilanjutkan dengan studi lapangan guna membuat purwarupa sesuai rancangan yang telah dibuat, implementasi, uji coba serta analisa hasil uji coba.

\section{Perancangan perangkat keras}

Pembuatan purwarupa diawali dengan blok diagram yang dapat dilihat gambar 3 .

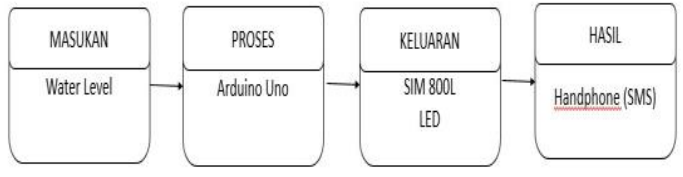

Gambar 3. Diagram blok rangkaian

Water Level digunakan sebagai media masukan mikrokontroller Arduino Uno sehingga pada saat ketinggian air melebihi batas maka datang perintah akan dikirimkan SIM 800L yang terhubung mikrokontroller untuk menyalakan LED dan mengirim SMS.

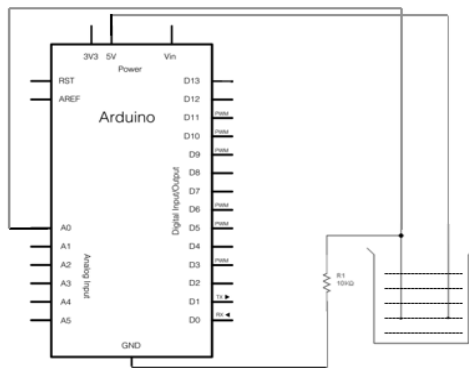

Gambar 3. Rangkaian Water Level yang terhubung Arduino Uno

Simulasi air pada sungai menggunakan wadah air yang isi nya dapat di buat bervariasi ketinggian air nya dengan satuan pengukuran menggunakan millimeter (mm).

Prinsip kerja Water Level pada dasarnya sebagai pembaca ketinggian air yang di hasilkan oleh air yang mengenai lempengan bergaris garis pada sensor tersebut. Semakin banyak air yang mengenai permukaan bergaris garis maka hambatan nya semakin kecil dan sebaliknya. Pembacaan ketinggian air menggunakan fungsi pembaca pada analog yang dicelupkan ke air dan akan dibaca oleh lempengan water level,Pada simulasi ini ketinggian air dari meter(m) di simulasikan menjadi mili meter $(\mathrm{mm})$ maka ketika ketinggian air terdeteksi $(0 \mathrm{~cm}$ $-90 \mathrm{~cm})$ yang di simulasikan $(0 \mathrm{~mm}-$ $5 \mathrm{~mm})$ maka keadaan LOW dan $(90 \mathrm{~cm}-1$ $\mathrm{m})$ yang di sumalikan menjadi $(10 \mathrm{~mm}-$ 40mm ) maka keadaan HIGH. Pin digital A0 (Serial Data Input/Output Line) 
berfungsi sebagai mengetahui ketinggian air untuk mengaktifkan Water Level. Tegangan yang dihubungkan pada pin VCC terhubung pada pin 5V Arduino Uno dan pin GND terhubung pada pin GND yang terdapat dalam mikrokontroller Arduino Uno

SIM800L adalah untuk mengirim SMS, calling, transfer data melalui Global System for Mobile (GSM) dalam penelitian ini mengirim sms ke no "08129099837827" di SIM800. Fungsi

Dual Tone Multiple Frequency (DTMF) adalah piranti semikonduktor yang dirancang untuk digunakan pada sistem dial pada pesawat telepon. DTMF membangkitkan suatu sinyal nada yang merupakan kombinasi dari 2 buah nada yang memiliki frekuensi rendah dan frekuensi tinggi. Dilengkapi juga fungsi Bluetooth, FM \& Embedded AT. Modul SIM 800L yang digunakan pada penelitian ini adalah modul SIM 800L memiliki RX (Receiver X) sebagai penerima data, TX (Transmitter $\mathrm{X}$ ) sebagai adalah pin yang berfungsi untuk mengirimkan data berupa teks yang akan diproses oleh mikrokontroler Arduino Uno.

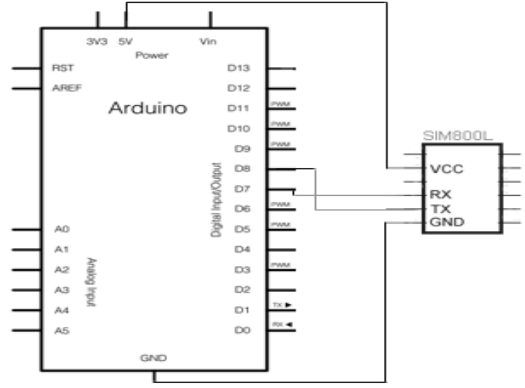

Gambar 4. Rangkaian modul SIM 800L yang terhubung Arduino Uno

Prinsip kerja SIM 800L pada dasarnya sebagai pengirim SMS. Pada penelitian ini modul SIM 800L digunakan untuk mengirimkan SMS ke telepon genggam yang di tuju,untuk memberikan informasi kondisi ketinggian air di tempat yang sudah di berikan sensor water level. Pin digital RX dan TX (Serial Data) berfungsi menerima dan mengirim perintah yang diinginkan Input/Output pada data

Light Emitting Diode yang digunakan LED biasa yang memiliki warna merah. Rangkaian LED diperlihatkan pada gambar 5. Prinsip kerja LED pada dasarnya hanya sebagai indikator bahwa Water Level terdeteksi pada ketinggian air $40 \mathrm{~mm}$. Apabila terdeteksi maka LED akan menyala. Pin LED pada kaki Anoda dihubungkan ke pin digital 13. Jika tidak terdeteksi ketinggian air maka LED akan mati.

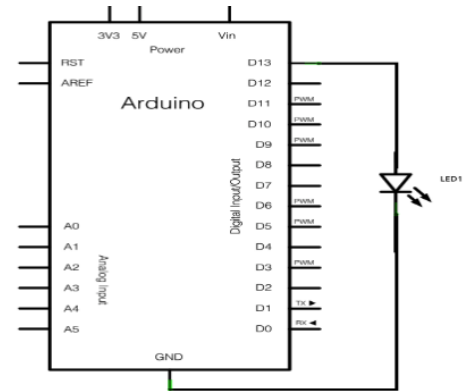

Gambar 5. Rangkaian LED yang terhubung ke Arduino Uno

Rangkaian keseluruhan merupakan rangkaian gabungan dari komponenkomponen yang di gunakan pada purwarupa ini dapat di lihat pada gambar 6. Semua rangkaian dari masing - masing bagian yang saling terhubung menjadi satu pada purwarupa pendeteksi banjir, yaitu Water Level sebagai media masukan data yang yang akan dikirimkan menuju mikrokontroller Arduino Uno untuk dapat diproses dan menghasilkan keluaran berupa SMS ke Handphone, dan lampu LED yang menyala sebagai pemberitahu apabila air sudah melebihi kapasitas hasil yang digunakan sebagai pendeteksi kebanjiran. 


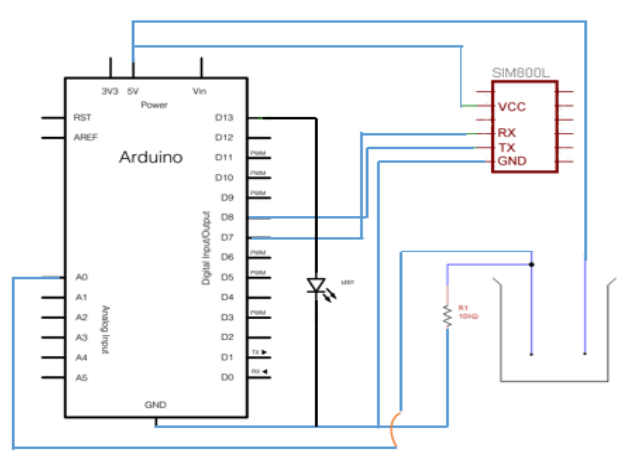

Gambar 6. Rangkaian purwarupa penyampaian informasi ketinggian air berbasis mikrokontroller Arduino Uno

\section{Perancangan perangkat lunak}

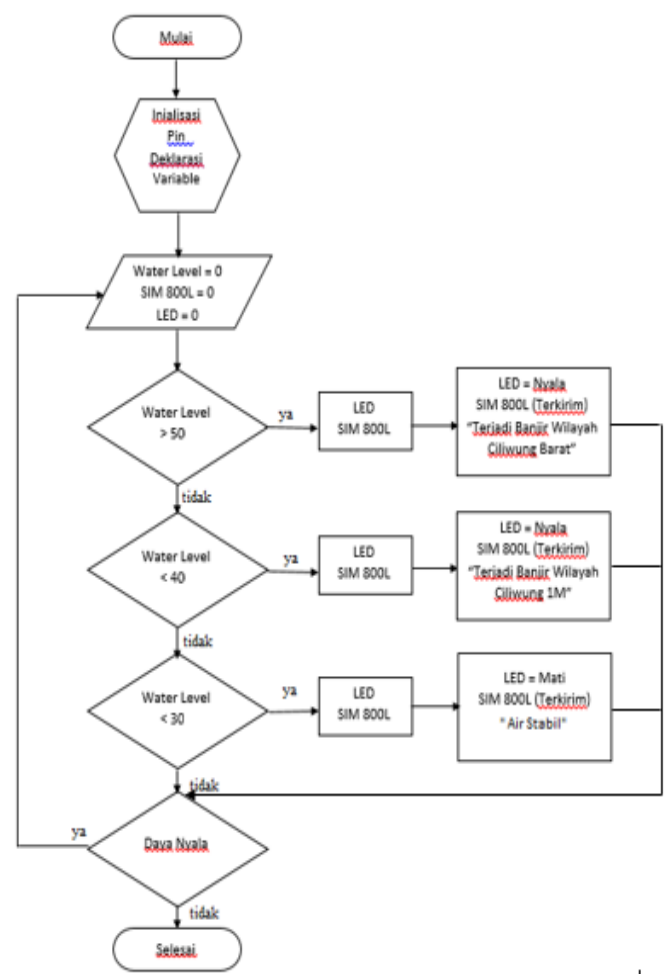

Gambar 7. Diagram alur rangkaian

Diagram alur purwarupa dapat dilihat pada gambar 7. Langkah pertama akan dilakukan inisialisasi semua. LED kondisi low artinya LED dalam kondisi mati. SIM 800L tidak mengirim pesan. Kemudian Water Level untuk mendeteksi ketinggian air, untuk memulai alat yang akan untuk dijalankan. Apabila Water Level mendeteksi kapasitas berlebih, maka $L E D$ menyala dan SIM 800L mengirim pesan.
Pemograman mikrokontroler agar alat tersebut dapat bekerja sesuai dengan prinsip kerja alat. Langkah pertama yang dilakukan yaitu membuka aplikasi IDE Arduino.

Setelah membuka aplikasi IDE Arduino, langkah selanjutnya yaitu menuliskan sketch program pada lembar kerja yang telah tersedia dengan sketch program purwarupa penyampaian informasi ketinggian air. Setelah sketch program selesai dibuat, selanjutnya dilakukan compile program untuk memeriksa ada atau tidaknya kesalahan penulisan coding program. Proses compile dapat dilihat pada gambar 8 .

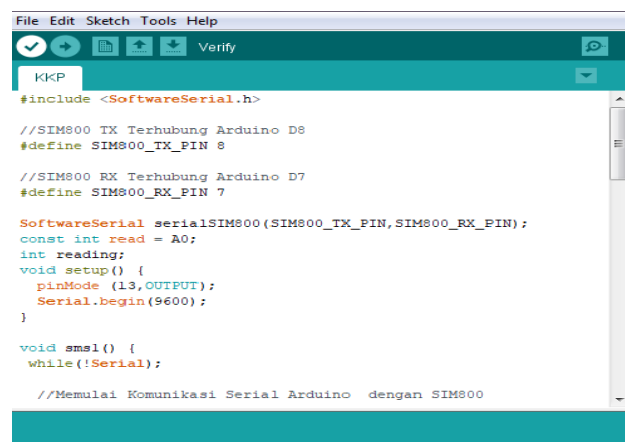

Gambar 8. Proses compile pada IDE Arduino

Setelah program decompile dan apabila tidak terjadi kesalahan maka program dapat diunggah ke Arduino Uno. Sebelum mengunggah program terlebih dahulu dilakukan pengaturan jenis board pada Arduino yang dengan cara pilih tools - board- Arduino Uno, selanjutnya dilakukan pengaturan pengaturan port dengan cara pilih tools- port- COM5 (Arduino Uno). Setelah pengaturan selesai, maka program siap di unggah.

\section{HASIL DAN PEMBAHASAN}

Proses pengujian yang akan dilakukan pada model bertujuan untuk mengetahui prinsip kerja dari alat dan program yang telah dibuat sesuai dengan yang akan dicapai sehingga diperoleh suatu 
kebenaran dari masing bagian - bagian unit yang saling terhubung dalam sistem tersebut.

\section{Pengujian teknis}

Pengujian teknis merupakan pengujian pada semua rangkaian secara bergantian dengan melakukan pengukuran spesifikasi besaran listrik yang bekerja pada komponen, dilakukan dengan menggunakan multimeter yang berfungsi untuk mengetahui besaran tegangan atau voltage. Pengukuran dengan mengamati serial monitor, Pengukuran dilakukan pada saat seluruh rangkaian pada tiap blok saling terhubung. Rangkaian ini terdiri dari rangkaian Water Level, rangkaian LED, rangkaian SIM 800L yang dilakukan dengan pengukuran pada titik tertentu.

Pengujian Water Level menggunakan multimeter dan dapat terlihat bahwa Water Level ketika terkena air mendapat masukan dan berhasil akses ke mikrokontroller. Hasil yang diperoleh menunjukan keluaran berupa nilai angka. Namun jika Water Level tidak dapat daya maka tegangan terdeteksi 0 volt.

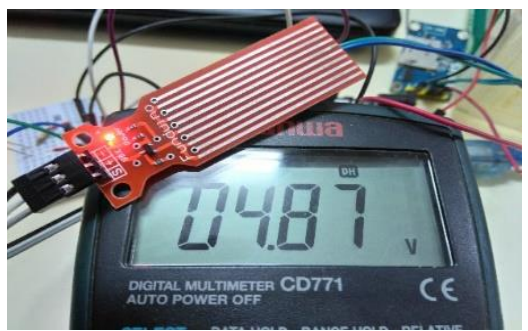

Gambar 9. Hasil pengujian water level dengan keadaan menyala

Tabel 1 merupakan hasil pengujian sensor water level agar dapat digunakan sebagai masukan purwarupa yang kemudian akan diteruskan ke rangkaian pemroses.

Tabel 1. Hasil pengujian Water Level

\begin{tabular}{|l|c|c|}
\hline No & $\begin{array}{c}\text { Water Level } \\
(\mathrm{mm})\end{array}$ & Hasil \\
\hline 1 & 0 & Tidak mendeteksi air \\
\hline
\end{tabular}

\begin{tabular}{|l|c|c|}
\hline 2 & 1 & Tidak mendeteksi air \\
\hline 3 & 3 & Tidak mendeteksi air \\
\hline 4 & 5 & Tidak mendeteksi air \\
\hline 5 & 7 & Mendeteksi air \\
\hline 6 & 9 & Mendeteksi air \\
\hline 7 & 10 & Mendeteksi air \\
\hline 8 & 20 & Mendeteksi air \\
\hline 9 & 30 & Mendeteksi air \\
\hline 10 & 40 & Mendetksi air \\
\hline
\end{tabular}

Pengujian kedua pada rangkaian LED ini dilakukan pada titik keluaran berupa menampilkan menyala lampu. Pada titik keluaran rangkaian LED dihubungkan dari Arduino Uno sebagai pemroses dan hasil pada saat Water Level terendam air pada ketinggian tertentu seperti yang terlihat pada gambar 10.

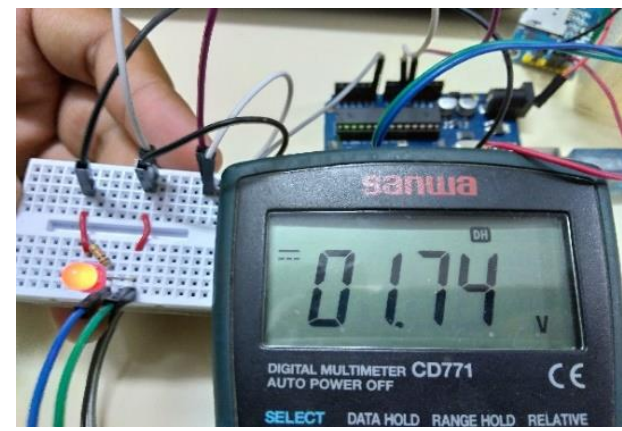

Gambar 10. Pengujian menampilkan hasil pada rangkaian LED menyala.

Pengujian keempat adalah SIM800L menggunakan multimeter sebagai alat bantu untuk mengetahui tegangan. Caranya adalah dengan menghubungkan pin VCC pada modul SIM800L dengan kabel merah pada multimeter pada multimeter dan pin GND pada modul SIM800L dengan kabel hitam pada multimeter. Setelah itu modul SIM800L akan di dapatkan ketika modul SIM800L mengirim pesan. 


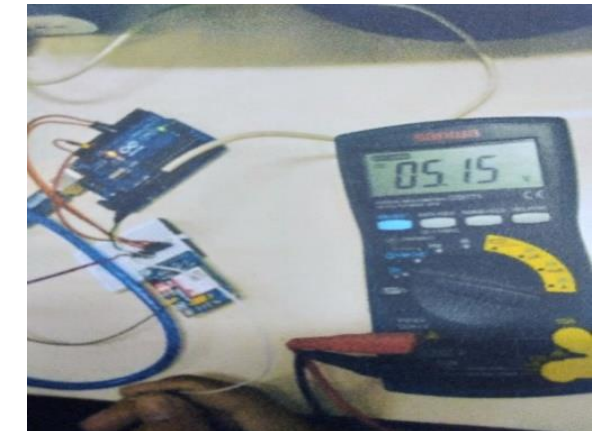

Gambar 11. Uji coba modul SIM800L.

Pada gambar 11 terlihat bahwa modul SIM800L tidak sedang mengirim sms memiliki tegangan $0 \mathrm{~V}$. Sedangkan saat SIM800L sedang mengirim SMS memiliki tegangan sebesar $5 \mathrm{~V}$.

\section{Pengujian fungsional}

Pengujian fungsional yang dilakukan pada rangkaian ini berbeda dengan pengujian teknis yang dilakukan sebelumnya. Pengujian teknis dilakukan untuk mengetahui spesifikasi besaran fisik dan kondisi komponen, sedangkan pengujian fungsional dilakukan untuk mengetahui setiap kinerja rangkaian apakah telah berjalan dan berfungsi dengan baik sesuai yang diharapkan atau tidak.

Sebelum melakukan pengujian secara fungsional, rangkaian di hubungkan terlebih dahulu ke catu daya. Setelah dihubungkan ke catu daya maka selanjutnya dilakukan proses pengujian. Dapat dilihat pada gambar 12 ketika alat sedang dalam keadaan aktif. Gambar 13 memperlihatkan kondisi dalam keadaan banjir dan gambar 14 memperlihatkan kondisi dalam keadaan darurat.

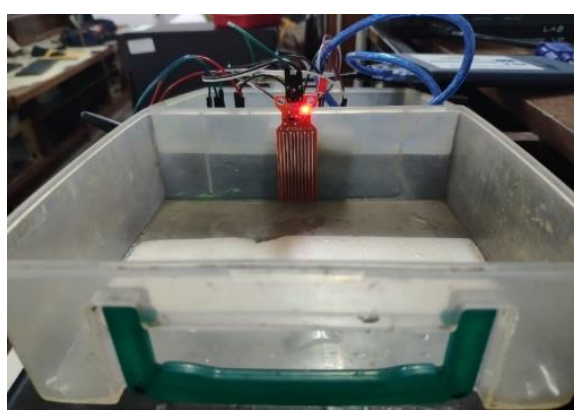

Gambar 12. Purwarupa dalam keadaan aktif

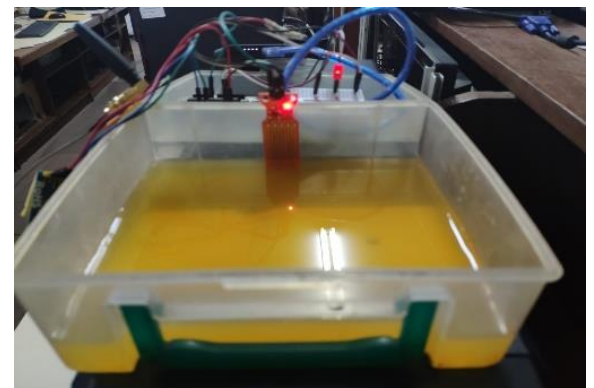

Gambar 13. Tampilan saat kondisi banjir

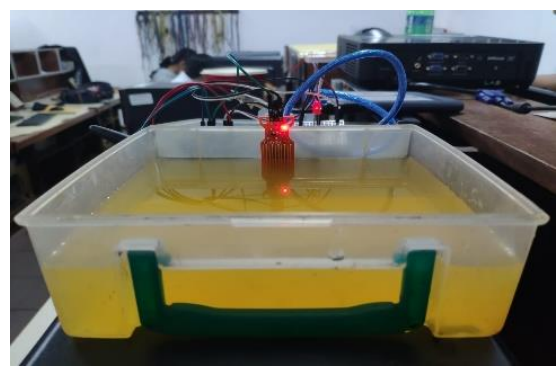

Gambar 14. Kondisi dalam keadaan kondisi darurat

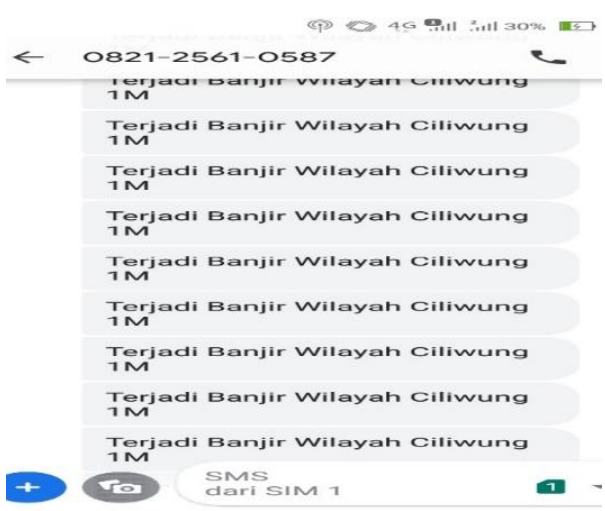

Gambar 15. Tampilan pada saat pemberitahuan ketinggian air 1 meter 


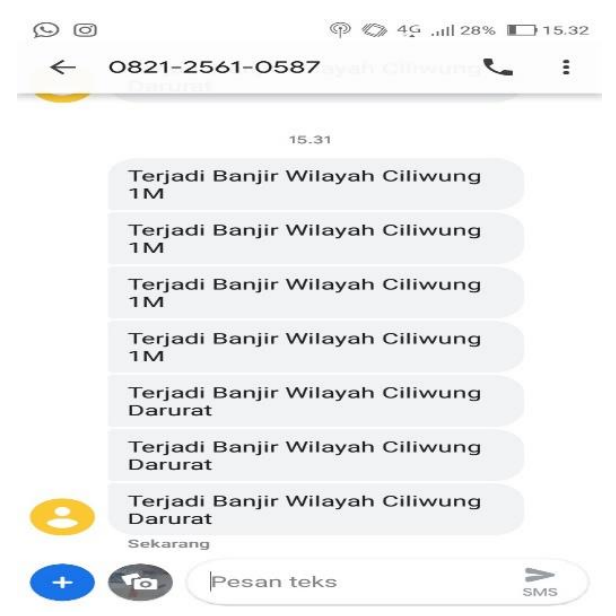

Gambar 16. Tampilan pada saat pemberitahuan keadaan banjir darurat

Dapat diamati pada gambar 15, pengujian saat Water Level terkena air 40 mm maka akan mengirimkan SMS seperti gambar 15 diatas. Serta gambar 16 dengan Water Level terkena melebihi ketinggian $40 \mathrm{~mm}$ maka akan mengirimkan SMS.

Pengujian seluruh rancangan pada alat dilakukan dalam keadaan aktif, lalu menguji coba alat dengan menggunakan miniatur yang mewakili sebagai pendeteksi banjir keadaan Water Level terlebih dahulu. Maka dapat diamati saat Water Level mendeteksi ketinggian air, setelah dapat mendeteksi air pada ketinggian melebihi $1 \mathrm{~m}$ kemudian mempengaruhi tegangan yang ada di dalam rangkaian masukan sehingga dari rangkaian masukan memberikan tegangan ke pin keluaran yaitu pin SIM 800L memberikan SMS dan LED menyala. Sebaliknya jika Water Level tidak mendeteksi air pada ketinggian melebihi 1 m tidak mengakses salah mikrokontroller tidak memberikan tegangan pada SIM 800L tidak memberikan SMS dan LED mati. Hasil uji coba rangkaian keseluruhan dapat dilihat pada tabel 2 .

Secara keseluruhan rangkaian dibagi menjadi tiga bagian yaitu masukan, pemroses, dan keluaran. Pada alat ini masukan terdiri dari pembacaan ketinggian kapasitas air yang dilakukan Water Level yang sebagai pusat kapasitas air yang akan didaftarkan sebagai ketinggian air, yang nantinya akan dikirimkan kebagian pemroses data (pengolahan data). Pemrosesan data merupakan bagian vital dari keseluruhan purwarupa alat ini dikarekan semua masukan yang diterima akan diproses dan akan menghasilkan sebuah keluaran yang disesuaikan dengan kebutuhan atau yang yang telah ditentukan, pemrosesan data tersebut diolah oleh ATmega 328p yang terdapat pada mikrokontroler Arduino mega. Data yang diperoleh dari hasil pemrosesan kemudian akan dikirim kebagian keluaran yaitu SIM 800L yang bekerja sebagai indicator atau pemberitahuan terbaca atau tidaknya

Tabel 2. Hasil uji coba rangkaian keseluruhan

\begin{tabular}{|l|l|l|l|l|}
\hline No & Water Level & SIM 800L & LED & Hasil \\
\hline $\mathbf{1}$ & $\begin{array}{l}\text { Tidak } \\
\text { Mendeteksi Air } \\
0 \mathrm{~mm}\end{array}$ & $\begin{array}{l}\text { Tidak Mengirim } \\
\text { SMS }\end{array}$ & Mati & $\begin{array}{l}\text { Tidak Mengetahui Keadaan } \\
\text { Wilayah Ciliwung }\end{array}$ \\
\hline $\mathbf{2}$ & $\begin{array}{l}\text { Mendeteksi Air } \\
\text { 20mm }\end{array}$ & $\begin{array}{l}\text { Mengirim SMS } \\
\text { "Air Wilayah } \\
\text { Ciliwung Stabil" }\end{array}$ & Menyala & $\begin{array}{l}\text { Mengetahui } \\
\text { Wilayah Keadaan } \\
\text { ketinggian air 20mm }\end{array}$ \\
\hline $\mathbf{3}$ & $\begin{array}{l}\text { Mendeteksi Air } \\
\text { 40mm }\end{array}$ & Mengirim SMS & Menyala & \\
\hline
\end{tabular}




\begin{tabular}{|c|c|c|c|c|}
\hline & & $\begin{array}{lr}\text { "Terjadi } & \text { Banjir } \\
\text { Wilayah } & \text { Ciliwung } \\
1 \mathrm{~m} " & \end{array}$ & & $\begin{array}{lr}\text { Mengetahui } & \text { Keadaan } \\
\text { Wilayah } & \text { Ciliwung } \\
\text { ketinggian air } & \text { 40mm }\end{array}$ \\
\hline 4 & $\begin{array}{l}\text { Mendeteksi Air } \\
60 \mathrm{~mm}\end{array}$ & $\begin{array}{l}\text { Mengirim SMS } \\
\text { "Terjadi Banjir } \\
\text { Wilayah Ciliwung } \\
\text { Darurat" }\end{array}$ & Menyala & $\begin{array}{lll}\text { Mengetahui } & & \text { Keadaan } \\
\text { Wilayah } & & \text { Ciliwung } \\
\text { ketinggian } & \text { air } & \text { Melebihi } \\
40 \mathrm{~mm} & & \\
\end{array}$ \\
\hline 5 & $\begin{array}{l}\text { Mendeteksi Air } \\
\text { 40mm }\end{array}$ & $\begin{array}{l}\text { Mengirim SMS } \\
\text { "Terjadi Banjir } \\
\text { Wilayah Ciliwung } \\
\text { 1m" }\end{array}$ & Menyala & $\begin{array}{l}\text { Mengetahui } \quad \text { Keadaan } \\
\text { Wilayah } \\
\text { ketinggian air } 40 \mathrm{~mm}\end{array}$ \\
\hline 6 & $\begin{array}{l}\text { Mendeteksi Air } \\
\text { 20mm }\end{array}$ & $\begin{array}{l}\text { Mengirim SMS } \\
\text { "Air Wilayah } \\
\text { Ciliwung Stabil" }\end{array}$ & Menyala & $\begin{array}{lr}\text { Mengetahui } & \text { Keadaan } \\
\text { Wilayah } & \text { Ciliwung } \\
\text { ketinggian air } 20 \mathrm{~mm}\end{array}$ \\
\hline 7 & $\begin{array}{l}\text { Tidak } \\
\text { Mendeteksi Air } \\
0 \mathrm{~mm}\end{array}$ & Mengirim & Mati & $\begin{array}{l}\text { Tidak Mengetahui Keadaan } \\
\text { Wilayah Ciliwung }\end{array}$ \\
\hline
\end{tabular}

kapasitas ketinggian air yang dibaca LED sebagai indikator lampu yang akan menyala yang menandakan kapasitas ketinggian air berlebih.

Pengujian secara keseluruhan di atas diketahui bahwa semua rangkaian pada sistem ini saling terhubung atau berkaitan satu dengan yang lainnya. Indikator sebagai pemberitahuan kondisi yang telah terjadi dan melakukan tindakan apa bila diperlukan. pengkatifan sistem ini dengan menghubungkannya dengan catu daya, pembacaan sensor, pengolahan kapasitas ketinggian air dan SIM 800L adalah inti dari purwarupa yang digunakan untuk pendeteksi kapasitas air berlebih.

\section{SIMPULAN}

Penelitian menghasilkan purwarupa rancangan sistem perekam data pada purwarupa penyampaian informasi ketinggian air menggunakan Water Level, Subcriber Identity Module (SIM) 800L ,
LED Berbasis Mikrokontroller Arduino Uno. Tahapan pngujian dan analisis telah diselesaikan, maka diperoleh beberapa kesimpulan sebagai berikut :

1. Water Level merbaca pada ketinggian air $0 \mathrm{~mm}$ sampai $40 \mathrm{~mm}$.

2. Purwarupa rancangan Pendeteksi Banjir Menggunakan Water Level, Subcriber Identity Module (SIM) 800L Dan Light Emitting Diode Berbasis Mikrokontroller Arduino Uno ini dirancang mampu memberikan informasi kebanjiran.

3. Pada Subcriber Identity Module (SIM) 800L akan menjadi bagian yang saling berpengaruh karena jika kondisinya terpenuhi maka sistem Pendeteksi Banjir akan mengirimkan SMS.

4. Hasil pengujian yang dilakukan pada rancangan sistem ini dapat bekerja dalam dua kondisi yaitu pada Water Level dengan melebihi ketinggian air $1 \mathrm{~m}$ maka akan mengaktifkan LED nyala 
dan SIM 800L memberi peringatan melalui SMS.

5. Alat ini membutuhkan catu daya sebesar $5 \mathrm{~V}$ dan menghasilkan tegangan pada setiap komponen Water Level sebesar $5 \mathrm{~V}$ jika melakukan tiap mendeteksi pada saat diaktifkan ke SIM 800L dan LED.

Saran untuk penelitian guna pengembangan untuk dapat diterapkan sebagai sistem bisa ditambahkan buzzer sebagai peringatan masyarakat sekitar DAS dan dapat dihubungkan menggunakan Internet on Things (IoT)

\section{DAFTAR PUSTAKA}

[1], Alfred Tenggono, Yovan Wijaya, Erick Kusuma, Welly, "Sistem monitoring dan peringatan ketinggian air berbasis WEB dan SMS Gateway", Jurnal Ilmiah SISFOTENIKAJ.5(2). 119-129, 2015

[2] Deosa Putra Caniago. “ Perancangan Papan Informasi Mahasiswa berdasarkan Real Time Clock pada Labor Elektro ITEBA dengan Memanfaatkan Fasilitaas Short Message Service (SMS)" , Jurnal Teknologi Dan Sistem Informasi Bisnis Vol. 4 No. 1 Januari 2022 DOI https://doi.org/10.47233/jteksis.v4 i1.393 ISSN :2655-8238, h171, 2022

[3] Davis,Gordon B., Andres S, Adiwardana. Bob Widyahartono, "Kerangka dasar sistem informasi manajemen" (Andreas S. Adiwardana, Bob Widyahartono), Pustaka Binaan Pressindo, Jakarta, 1993

[4] Raymond Jr. \& George, "Sistem Informasi Manajemen" (Hendra Teguh ; Agus Widyantoro) , Indeks, Jakarta, 2004
[5] Winoto,A, "Mikrokontroler AVR atmega8/16/32/8535 dan pemogramannya dengan bahasa $\mathrm{C}$ pada WinAVR", Informatika Bandung, Bandung, 2010

[6] Heri Andrianto, Aan Darmawan, "Arduino belajar cepat dan pemrograman" , Informatika, Bandung, 2015

[7] Hadi Syahputra, "Perancangan Otomatisasi Pewarnaan Pola Sablon Baju Pada Industri Creativ Dengan Menggunakan Arduino Mega 2560" , Jurnal Teknologi Dan Sistem Informasi Bisnis Vol. 4 No. 1 Januari 2022 DOI : https://doi.org/10.47233/jteksis.v4i 1.377 ISSN :2655-8238, h 97, 2022

[8] Iwan Setiawan, "Buku Ajar Sensor dan Tranducer", Semarang 2012.

[9] Abdul Kadir, "Arduino dan Sensor, Tuntunan praktis mempelajari penggunaan sensor untuk aneka proyek elektronika berbasis Arduino", Penerbit Andi, Yogyakarta, 2018.

[10] Edwin \& Kristiadjie, Handiyanta, " Alat Pemantau Pengendali dan Penyampaian Informasi Status Operasi Mesin Secara Otomatis", TESLA, 8(2), 152, 2016.

[11] Antoni Susiono, Handy Wicaksono., dan Hany Ferdinando, "Aplikasi Scada System pada Miniatur Water Level Control", Surabaya: Universitas Kristen Petra Surabaya, 2006.

[12] Ummul Khair S, "Alat pendeteksi ketinggian air dan keran otomatis menggunakan water level sensor berbasis Arduino Uno", Wahana Inovasi, 9 (1) ISSN : 2089.

[13] Dian Pangest, Abdul Muid, Uray Ristian, Uray, "Purwarupa system informasi titik lokasi dan intensitas curah hujan di kota Pontianak", Jurnal Coding, Sistem Komputer 
Untan, 6(1), ISSN : 2338-493X Volume 06, No 03 hal. 247-254 247, 2018

[14] Lanini Milenise Fisabili, Tir Wahyu Oktaviana Putri, "Rancang bangun sistem pemadam kebakan box paneloutdoor menggunakan Arduino Uno berbasis GSM SIM 800L", Jurnal ilmiah Sutet,Juni 2021, 1(1), 5, pISSN 23561505,eISSN 2656-9175, https://doi.org/10.33322/sutet.v1

[15] L. Hakim, \& J Halim, "Peringatan Kebakaran Hutan Menggunakan
Sensor Api , Suhu dan Asap", Seminar Nasional Teknologi Informasi Dan Komunikasi, 14, 26-38, 2018.

[16] Lamhot Sitorus,(2015), “Algoritma dan pemrogaman", Yogyakarta, Penerbit Andi, 2015.

[17] Wirdasari, Dian., (2010) Membuat program dengan menggunakan bahasa $C$, Jurnal SAINTIKOM, 8(1),1 Januari 2010. 